\title{
Experimental Research on Zirconia Resistance to Occlusal Stresses
}

\author{
RALUCA MONICA COMANEANU ${ }^{1}$, LOREDANA ELENA BORDEA ${ }^{2 *}$, VIVIYANA PARASCHIV ${ }^{1}$, OANA BOTOACA ${ }^{1}$, FARAH BECHIR ${ }^{2}$, \\ MIHAIL TARCOLEA ${ }^{3}$, COSTIN COMAN ${ }^{1}$, MIHAELA TANASE ${ }^{4}$ \\ ${ }^{1}$ Titu Maiorescu University of Bucharest, Faculty of Dental Medicine, 67A Ghe. Petrascu Str., 031593, Bucharest, Romania \\ 2UMFST Tirgu Mures, Faculty of Dental Medicine, 38 Ghe. Marinescu Str, 540139, Tirgu Mures, Romania \\ ${ }^{3}$ Politehnica University of Bucharest, Faculty of Material Science and Engineering, 313 Splaiul Independentei, 060042, Bucharest, \\ Romania \\ ${ }^{4}$ Carol Davila University of Medicine and Pharmacy, Faculty of Dental and Medine, 37 Dionisie Lupu Str., 020022, Bucharest, \\ Romania
}

\begin{abstract}
FEM studies were made on a zirconia dental bridge of 4 elements with supports on 2.4 and 2.7, and edentation on 2.5 and 2.6. Appling a compressive force of $350 \mathrm{~N}$ on $Z$ direction, quite normal for mastication, was analyzed the behavior of the dental bridge. Zirconia, although having a high mechanical strength, is fragile when rotation or bending movements occur. The analysis reveals some bridge deficiencies, which may be due either to inaccuracies in the prosthetic abutment construction (especially in relation to their inclination), to the technique of realization or to insufficient dental support. In our study, the most vulnerable elements are the crowns on teeth 2.4 and 2.7. Finite element analysis, highlighting possible structural and design deficiencies, may be a solution to improve dental bridges. The only disadvantage of the finite element analysis that was performed before the actual restoration is related to the fact that performing the simulations involves a time-consuming phase.
\end{abstract}

Keywords: zirconia, FEA, dental bridge

The availability of different dental ceramic systems provides solutions for different types of restorative problems in esthetic dentistry, from conservative to extensive [1].

Zirconia is one of the most utilized ceramics nowadays due to its excellent electronic, thermal, optical and mechanical properties [2]. Pure zirconia ( $\mathrm{ZrO}_{2}$ ) has a high melting point $\left(2680^{\circ} \mathrm{C}\right)$ and low thermal conductivity [3].

The traditional monochromatic zirconia used in dentistry is Yttrium-stabilized polycrystalline tetragonal zirconia (Y-TZP), which has high fracture hardness, ranging from 5 to $10 \mathrm{MPa} \cdot \mathrm{m}^{1 / 2}[4,5]$, and shear strength ranging from 900 to $1400 \mathrm{MPa}[6,7]$. restorations can be estimated using in vitro and in vivo tests, while randomized clinical trials can provide information on the long-term prognosis of protheses [8].

Clinical trials, however, require time to collect data, involve increased costs, and the presence of a large number of volunteers to obtain results of appropriate statistical relevance $[9,10]$. For these reasons, experimental simulations of clinical situations have become important tools for achieving rapid and standardized results. [10]

Although simplified specimens, such as discs and reduced samples used for in vitro tests, are useful for determining material hardness and estimating local stresses that can lead to clinical failure, we cannot take into account the influence of prosthetic geometry on tension distribution [11, 12].

When using specimens that simulate the shape of fixed prosthetic crowns, the biomechanical behavior is close to
The clinical behavior of materials used for dental

the actual clinical situation, but the evaluation of tension distribution in complex geometry bodies is limited [1315]. This situation can be solved by using finite element analyzes, which are a quick and relatively cheap method for investigating tension distribution in complex design structures such as dental restorations [16].

\section{Experimental part}

We studied a zirconia dental bridge with 4 elements to solve a prosthesis for edentation of 2.5-2.6.

The dental bridge STL file was imported into ANSYS $₫$ software, dedicated for simulation through finite element analysis (fig. 1).

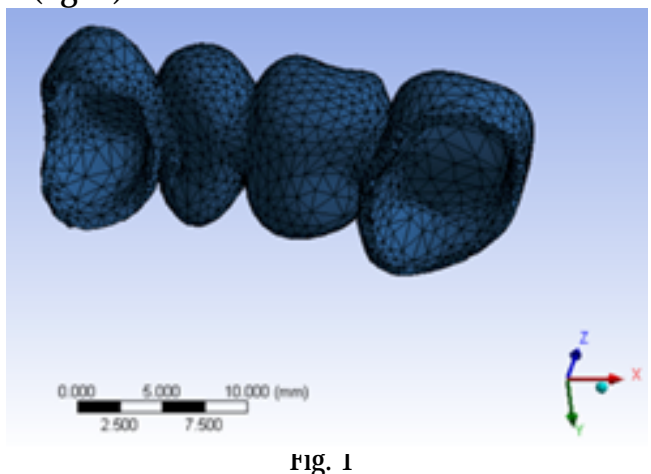

The 4-element bridge (2.4-2.5-2.6-2.7) imported into ANSYS and divided into finite elements

Zirconia properties $\left(\mathrm{ZrO}_{2}\right)$ were those centralized in tables 1 and 2.

Table 1

ZIRCONIA -ELASTIC PROPERTIES

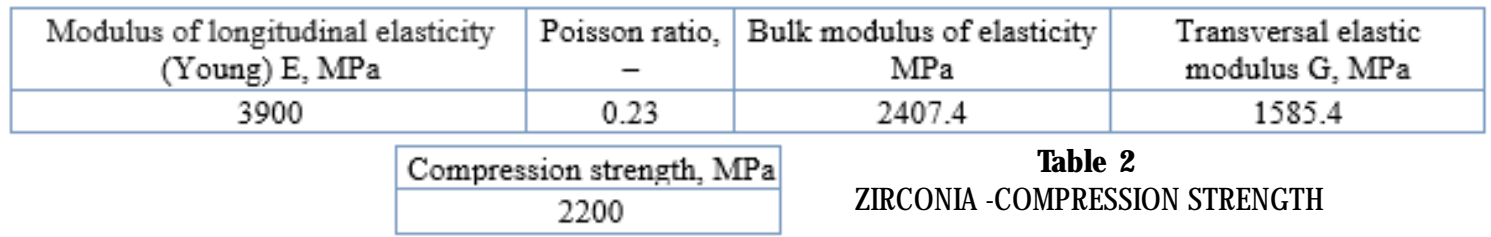

\footnotetext{
* email: lori.stoica@yahoo.com; Phone: 0731318081

All authors had equal scientific contribution in publishing this material.
} 
The dental bridge was divided into 7.277 finite elements interconnected by 13.664 nodes. The experiment was conducted at body temperature $\left(36^{\circ} \mathrm{C}\right)$, applying a Z-axis compressive force of $350 \mathrm{~N}$.

The dental restoration support was considered, according to the clinical situation, on the internal faces of the aggregation elements and the experimental force of $350 \mathrm{~N}$ was applied vertically downwards (in the negative direction of the Z-axis) and was considered evenly distributed on the occlusal contact surfaces of the four components of the dental bridge.

\section{Results and discussions}

For the zirconia bridge there were determined: the total deformation, directional deformations in $X, Y$ and $Z$ direction, the equivalent elastic strain, the maximum principal elastic strain, the maximum shear elastic strain, equivalent total strain, the normal elastic strain in the $X, Y$ and $Z$ directions, the shear elastic strain on $X Y, Y Z$ and $X Z$ planes, equivalent stress, maximum principal stress, maximum shear stress, stress intensity, normal stress in $X, Y$ and $Z$ directions, and shear stresses on $X Y, Y Z$ and $X Z$ planes.

Absolute maximum elastic deformations occur orally on the dental bridge body, but the absolute values are very small, of the order $10^{-2}-10^{-4}$ millimeters.

As for the deformation in $X$ direction, the extremes appear on the elements 2.4 and 2.5 on the cusps; the values of these elastic deformations are, however, very small (microns).

The simultaneous presence of compression and elongation deformations on the same element, as we can see in this case on the crown of mesial aggregation, can affect the bridge's behavior over time.

Even if the extreme values in the case of the Y-direction deformation have opposite signs, given their low values, they should not create biomechanical problems. However, the presence of such elastic deformation tendencies may lead to deterioration of the bridge over time.

The elastic deformations corresponding to $Z$ direction are both positive (buccal elongation) and negative (compression to the oral), with relatively small values $\left(10^{-1} \ldots 10^{-2}\right.$ millimeters). Maximum values appear on 2.4 and 2.7; however, the emergence of this spectrum of opposite direction deformations can induce problems over time and are due to a poor design of the crowns, or relatively insufficient support.
The differences between the extreme values of the equivalentelastic deformation are globally quite small, both positive, and are manifested on the distal aggregation element. It can also be seen that the bonding zones between the restoration components have slightly larger deformations than the actual crowns, naturally as a result of their smaller dimensions. The maximum main elastic deformation also has different values of the extremes $(+$ and -$)$ which manifest in particular between the two elements that make up the dental bridge body (figs. 2-7).

The maximum shear elastic strain has relatively small positive values (elongation), but the range of variation of the values (differences about 104 times between the extreme values) is rather wide and manifests especially on the distal element of the restoration.

We note the presence of the slight elongation tendency determined by compression stress on Z direction, with quite large differences between the extreme values $(\sim 104)$, which manifests especially on the crown 2.7 .

As for the equivalent elastic strain, we notice the presence of positive values (slight tendency of elongation determined by compression in Z direction), with quite large differences betw een extreme values ( 104). The extreme values are also positioned on the distal element.

Normal elastic strains in the $X$ direction are small in absolute value, but vary from negative to positive values, resulting in unwanted compression / stretching effects. Extremes are manifested at the level of the restoration body.

The normal elastic strain in the $Y$ direction are small in absolute value but range from negative to positive values, which also leads to undesirable compression / stretching effects between the supports in positions 2.4 and 2.7. High deformation values can be noted in the longitudinal axis of the restoration.

The normal elastic strain in the $Z$ direction is small in absolute value, but varies from negative values to positive values, resulting in unwanted compression / stretching effects. The extremities are manifested at the support elements 2.4 and 2.7, but high values can also be seen on the occlusal surface.

In the case of the shear elastic strain on the XY plane, we notice similar variations as in previous analyzes, this time the differences between extreme positive and negative values appear on the distal element.

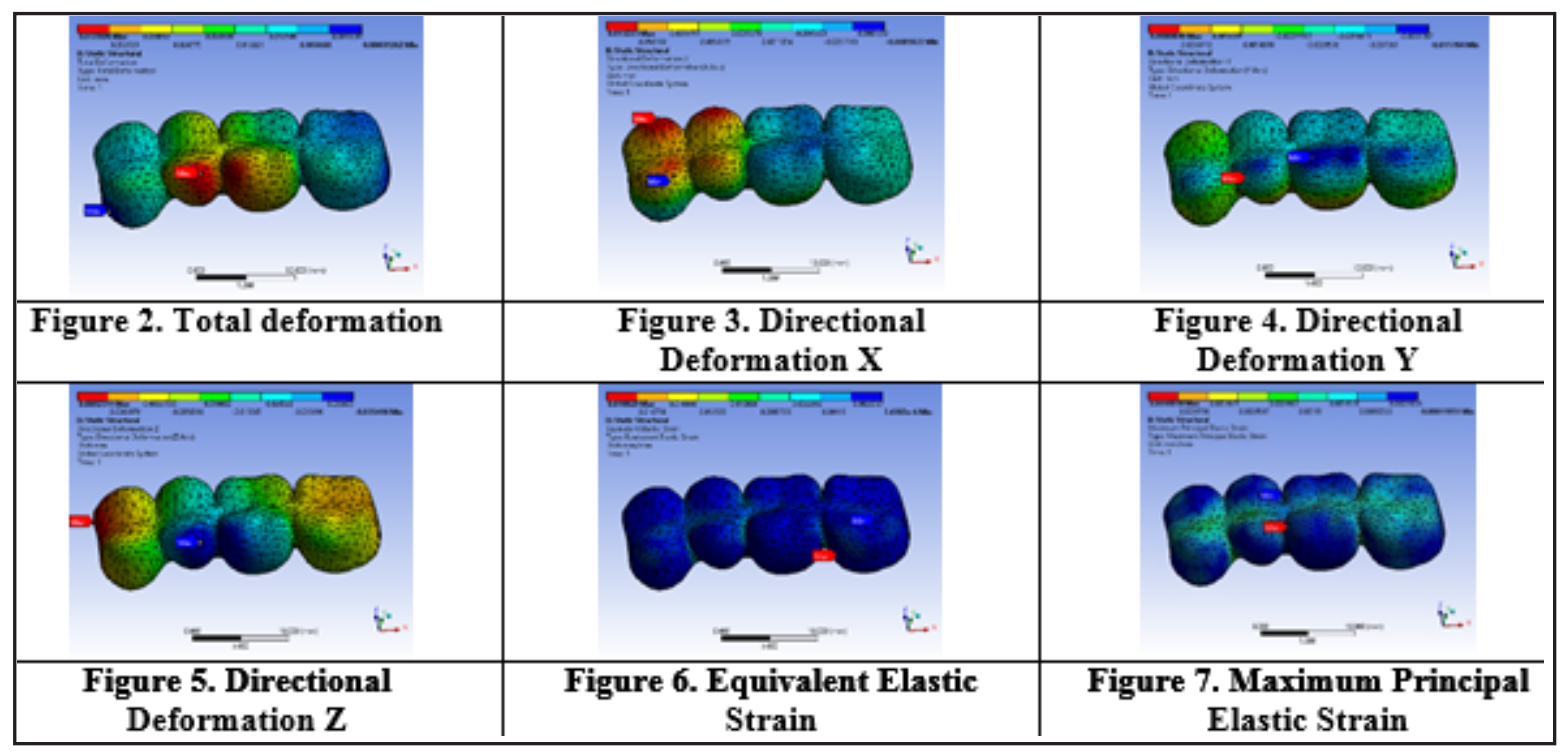


Shear elastic stain in the XZ plane are small in absolute value, but vary from negative values to positive values, resulting in unwanted compression / stretching effects. Extreme values are manifested at the aggregation elements 2.4 and 2.7 (figs. 8-16).

Equivalent stress has positive values (traction stress) and evolves widely, from practically 0 to over $70 \mathrm{MPa}$; the maximum value appears on the distal crown, but is within acceptable limits.

The maximum principal stress has the extreme values in the central portion of the restoration, of low values, but these create a tendency to rotate around the elements 2.4 and 2.7 because of the opposite directions of action.

The maximum shear stress has positive but relatively low values over a relatively wide range $(0 \ldots 40 \mathrm{MPa})$, but within acceptable limits.

Stress intensity has positive but relatively low values, over a relatively wide range, within acceptable limits. The extreme values are located at the level of the crown of the tooth 2.7.
The normal stress in the $X$ direction has the extreme values of different signs and they occur at the middle of the dental bridge, causing a spin effect around the axle's longitudinal axis. However, the range in which values evolve is not exaggerated.

The normal stress in the $Y$ direction has extreme values of different signs and they occur at the level of the distal element. On the other hand, higher values can be observed in the longitudinal axis of the crown.

Normal stress in the $Z$ direction has extreme values of different signs and these are manifested on the two aggregation elements of dental bridge, which leads to a tendency to bend between the two supports in the direction of the $Z$ axis (figs. 17-25).

The shear stress in the $X Y$ and $Y Z$ planes have extreme values of different signs and these are manifested at the level of the distal element. Extremes of opposite signs produce a shear tendency between the respective areas. However, the range in which values evolve is not exaggerated.
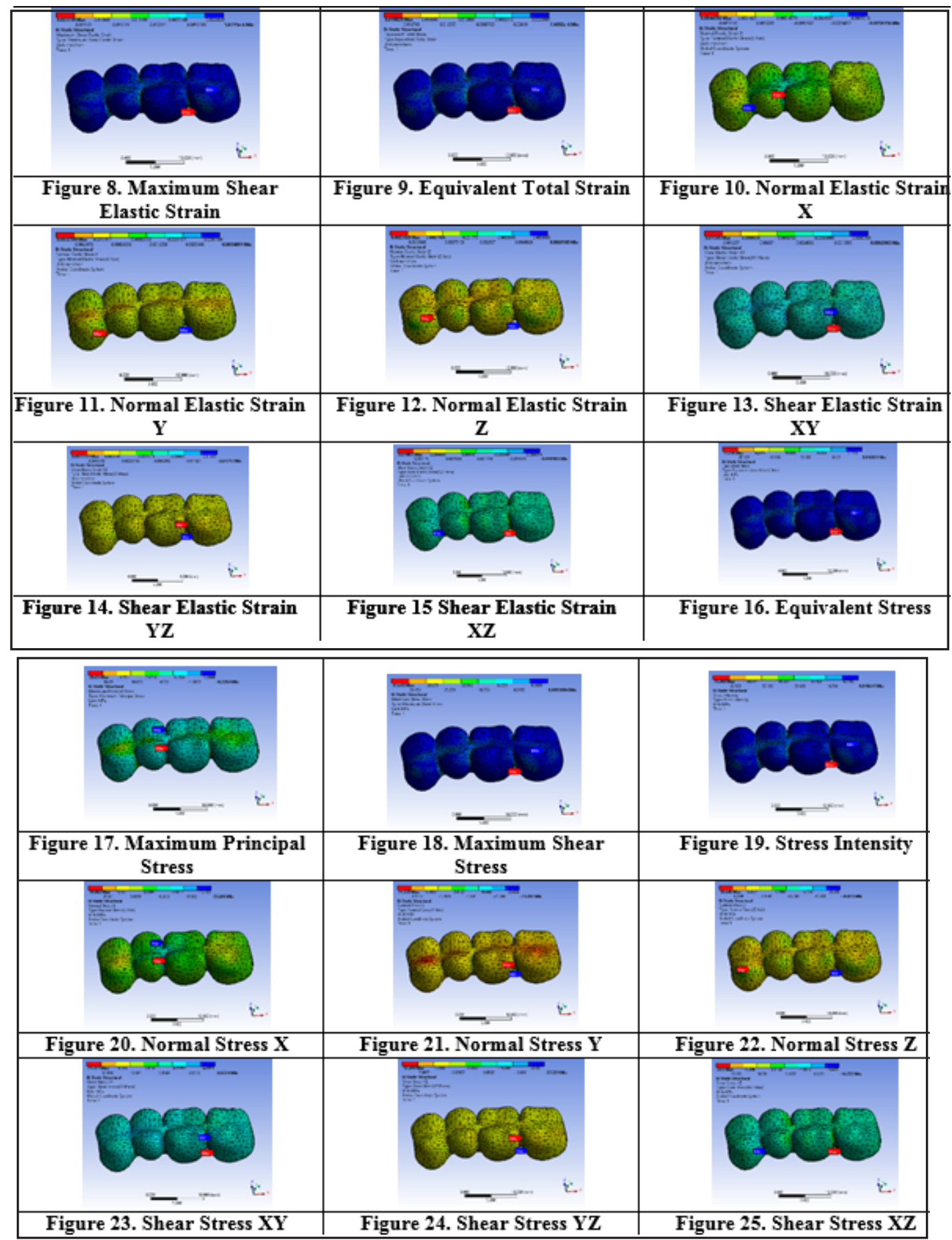
The shear stress in the $X Z$ plane has extreme values of different signs and these are manifested on the distal element, respectively, between the mesial aggregation component and the restoration body.

The requirements for an acceptable dental material are many, but one of the most important is their compatibility [17].

In the case of dental restoration, zirconia offers a combination of good mechanical properties with optical properties, chemical resistance and biocompatibility. [18]

Zirconia has been used in dentistry for more than 15 years with different indications, mainly for replacing metal in fixed prosthetic restorations to improve aesthetics. [19] However, the primary clinical complication related to the use of zirconia for fixed dental prostheses is the high fracture rate of porcelain with which it covers, varying between 15 and 54\%. [20, 21] Protocols to eliminate or reduce the possibility of cracking or fracture of porcelain include covering only in the gingival region or regions that are not loaded, and the adoption of lower heating and cooling rates during ceramic firing cycles [19,22].

The use of monolithic zirconia or the application of a minimal ceramic layer is now done frequently to reduce technical complications [23].

A recent systematic review [24] on zirconia fixed prosthetic restorations identified 12 studies showing 285 zirconia dentures with a $1.4 \%$ short-term failure rate due to fracture of the zirconia skeleton. However, the same study reported that ceramic-coated zirconia dentures had a failure rate of $14.7 \%$ due to porcelain fracture [24]. To alleviate this problem, the authors [24] recommended the use of porcelain zirconia only in regions not under occlusive stress or the use of monolithic zirconia.

Finite Element Analysis [25-28], is an important tool for understanding the mechanical behavior of prosthetic restorations and for optimizing their design in order to perform future tests [29].

Fischer etal. [30] used finite element analysis to evaluate the distribution of stresses in whole ceramic restorations. The authors noted the similar distribution of tensions in dental materials.

To extrapolate the results obtained by the finite element method to the clinical situation, it is important to appreciate the quality of the model to adequately represent the stress distribution within its structures. [31]

The models used in the finite element analyzes show a number of simplifications in relation to the clinical situation:

- the materials are considered to be homogeneous, isotropic and with linear elastic behavior

- the influence of cement bonding layer is neglected

- the effect of periodontal ligaments is not taken into account

- also, any defects in the structure or surface of dental materials are not taken into account. [32].

\section{Conclusions}

When establishing the geometry of the dental bridge, it is necessary to take into account the mechanical properties of the material from which it is made. Zirconia, although having a high mechanical strength, is fragile when rotation or bending movements occur.

The analysis reveals some bridge deficiencies, which may be due either to inaccuracies in the prosthetic abutment construction (especially in relation to their inclination), to the technique of realization or to insufficient dental support. In our study, the most vulnerable elements are the crowns on teeth 2.4 and 2.7 .
Finite element analysis, highlighting possible structural and design deficiencies, may be a solution to improve dental bridges.

The only disadvantage of the finite element analysis that was performed before the actual restoration is related to the fact that performing the simulations involves a timeconsuming phase.

\section{References}

1. POROJ AN, L., SAVENCU, C., POROJ AN, S., Rev. Chim.(Bucharest), 67, no.1, 2016, p. 123-126.

2.VALCU (HERBEI), E.E., MUSAT, V., JANK, M., OERTEL, S., Rev. Chim.,(Bucharest), 65, no. 5, 2014, p. 574.

3. MIHAI, L.L., PARLATESCU, I., GHEORGHE, C., ANDREESCU, C., BECHIR, A., PACURAR, M., CUMPATA, C.N., Rev. Chim.,(Bucharest), 65, no. 6, 2014, p. 725 .

4. BIDRA AS. J Esthet Restor Dent 2011;23:219-36.

5. TISCHLER M, PATCH C, BIDRA AS, The journal of prosthetic dentistry, 2018, e1-e6.

6. DENRY I, KELLY JR. J Dent Res 2014;93:1235-42.

7. MIYAZAKI T, NAKAMURA T, MATSUMURA $H, B A N$ S, KOBAYASHI T. J Prosthodont Res 2013;57:236-61.

8. DELLA BONA A, BORBA M, BENETTI P, DUAN Y, GRIGGS JA, Journal of Dentistry, Volume 41, Issue 5, May 2013, Pages 412-419.

9. HICKEL R, ROULET JF, BAYNE S, HEINTZE SD, MJ OR IA, PETERS M, et al. J ournal of Adhesive Dentistry 2007;9:121-47.

10. ROSENTRITT M, BEHR M, VAN DER ZEL JM, FEILZER AJ. Dental Materials 2009;25:348-52.

11. KELLY JR, BENETTI P, RUNGRUANGANUNT P, BONA AD. Dental Materials 2012;28:41-51.

12. KELLY J R. Journal of Prosthetic Dentistry 1999;81:652-61.

13. VERDONSCHOT N, FENNIS WM, KUIJS RH, STOLK J, KREULEN CM, CREUGERS NH. International J ournal of Prosthodontics 2001;14:310-5.

14. BURKE FJ. Quintessence International 1996; 27:115-21.

145. THOMPSON GA. Dental Materials 2000; 16:235-43.

16. IMANISHI A, NAKAMURA T, OHYAMA T. J ournal of Oral Rehabilitation 2003; 30:818-22.

17. BECHIR, A., BECHIR, E.S., MANU, R., et al, Mat Plast, 53, no. 4, 2016, p. $661-665$

18. EARAR, K., GRIGOROIU, R., SCUTARIU, M.M., VASILE, E., ANTONIAC, A,. DRAGOMIR, L., GRADINARU, S., Rev. Chim. (Bucharest), 68, no.7, 2017, p. 1560-1564.

19. DENRY I, KELLY JR. J Dent Res 2014; 93:1235-42.

20.POZZI A, HOLST S, FABBRI G, TALLARICO M. Clin Implant Dent Relat Res 2015; 17(suppl 1):e86-96.

21. HEINTZE SD, ROUSSON V. Int J Prosthodont 2010;23: 493-502.

22. BENETTI P, KELLY JR, SANCHEZ M, DELLA BONA A. Dent Mater 2014; 30:554-63.

23. BIDRA AS, TISCHLER M, PATCH C.J Prosthet Dent 2018;119:220-4. 24. BIDRA AS, RUNGRUANGANUNT P, GAUTHIER M. Eur J Oral Implantol 2017; 10 (suppl 1):35-45.

25. COMAN, C., GHERGIC, D.L., PATROI, D.N., TARCOLEA, M., COMANEANU, R.M., BARBU, H.M., Mat. Plast., 53, no. 1, 2016, p. 91. 26. DRAGUS, L., TINU, A.S., COMAN, C., COMANEANU, R.M., GHERGIC, D.L., Rev. Chim. (Bucharest), 69, no. 9, 2018, p. 2594.

27. ORMENISAN, A., TARCOLEA, M., SUCIU, M., GRIGORAS, R.I., BERESESCU, F.G., VLASCEANU, D., HANCU, V.. COMANEANU, R.M., Mat. Plast., 52, no. 3, 2015, p. 373-375.

28. COSARCA, A.S., GRIGORAS, R., HANCU, V., COMAN, C., COMANEANU, R.M., MORARU, L., TARCOLEA ,M., ORMENISAN, A., Mat. Plast., 53, no 1, 2016, 135-138.

29. DE SANTIS R, MOLLICA F, PRISCO D, RENGO S, AMBROSIO L, NICOLAIS L. A., Biomaterials 2005;26:257-70.

30. FISCHER H, WEBER M, MARX R. J ournal of Dental Research 2003; 82:238-42.

31. VERDONSCHOT N, FENNIS WM, KUIJS RH, STOLK J, KREULEN CM, CREUGERS NH. International Journal of Prosthodontics 2001; $14: 310-5$.

32. DELLA BONA A, BORBA M, BENETTI P, DUAN Y, GRIGGS J A, J ournal of Dentistry, Volume 41, Issue 5, May 2013, p. 412-419.

Manuscript received: 14.10 .2018 